\title{
Incidence of adenovirus detected by immunoenzymatic assay from children hospitalized with acute gastroenteritis in Douala, Cameroon
}

\author{
Martin Luther Koanga MOGTOMO ${ }^{1 *}$, Helène Mystelle Ndomboh GHOGOMU ${ }^{1}$, Solange \\ Isabelle Tchoumbou KAMDJOUM ${ }^{1}$, Paul Martin BAANE ${ }^{2}$ and Annie Ngono NGANE ${ }^{1}$ \\ ${ }^{1}$ Department of Biochemistry, University of Douala, P.O. Box 24157 Douala, Cameroon. \\ ${ }^{2}$ Douala General Hospital, Cameroon. \\ *Corresponding author, Phone: 00237995034 44, E-Mail: koanga@yahoo.com
}

\begin{abstract}
Adenovirus is recognized as the most common cause of severe gastroenteritis in children less than 5 years of age. Due to the lack of recent reports about the surveillance of enteric adenovirus (EAd) infection in Cameroon, in this study we assessed the prevalence rate of HAV infection on 65 stool samples belonging to 65 paediatric patients hospitalized with acute gastroenteritis in the period October 2005-December 2005. The faecal samples were submitted to virological investigations by enzyme-linked immunosorbent assay (ELISA). Single adenovirus infections were detected in $43.1 \%$ (28/65 cases). According to age distribution, $44.7 \%$ (17/38 cases) of adenovirus infected children was one month to 5 years, 30.8\% (4/13 cases) was in the 6-10 year old age and $50.0 \%$ (7/14 cases) was in the 11-15 year age group. The epidemiological aspects of adenovirus infection, will contribute to assess the magnitude of the problem of adenovirus in different settings and to devise strategies for intervention.

(C) 2008 International Formulae Group. All rights reserved.
\end{abstract}

Keywords: Epidemiology, enteric adenovirus, acute gastroenteritis, hospitalized children

\section{INTRODUCTION}

Viral gastroenteritis is a common disease with a high morbidity reported worldwide especially in infant and the elderly. The mortality among children due to acute gastroenteritis is greater in developing than developed countries (Nguendo, 2007). Acute gastroenteritis consistently ranks as one of the top six causes of all deaths. If rotavirus group $\mathrm{A}$ is the commonest cause of acute gastroenteritis worldwide, enteric adenovirus is considered to be a significant global enteropathogen. This is also associated with sporadic outbreaks of acute gastroenteritis worldwide. Human adenovirus belongs to the Mastadenovirus genus of the family Adenoviridae (Kapikian et al., 2001). Fiftyone human adenovirus serotypes have been distinguished on the basis of their resistance to neutralization by antisera to other adenovirus serotypes. The various known adenovirus are classified into six subgenera from $\mathrm{A}$ to $\mathrm{F}$ based on their hemagglutination reaction to human and animal erythrocytes (De Jong et al., 1993; Schnurr and Dondero, 1993; De Jong et al., 1999). Among the six subgenera, the subgenus $\mathrm{F}$ adenoviruses are the most important etiologic agent of severe acute gastroenteritis, accounting for up to $20 \%$ of cases. They have a global distribution and current statement on comparable prevalence both in outpatients and hospitalized infants in developing as in developed countries (Nguendo, 2007; Moore et al., 1998). Infants and young children hospitalized for an enteric adenovirus infection are more likely to have persistent symptoms and to be admitted later in the course of their illness than those suffering from the more common rotavirus infection, in which the onset is acute and associated with dehydration. Enteric adenovirus and rotaviruses both produce as symptoms fever, vomiting, and watery diarrhoea but there are conflicting reports as 
to whether Enteric adenovirus infection results in a milder but more prolonged illness than rotavirus (Cruz et al., 1990; Jarecki-Khan et al., 1993). Due to the lack of recent reports about the surveillance of paediatric human adenovirus (HAV) infection in Cameroon, the objectives of the study were to determine the incidence of enteric adenovirus infection in infants and children hospitalized with acute gastroenteritis at the Douala general hospital.

\section{MATERIALS AND METHODS Patients}

Faecal samples were collected from 65 paediatric patients hospitalized with acute gastroenteritis in the period October to December 2005 at the infectious unit of the Douala General Hospital. Patients were consecutively recruited on the basis of acute gastroenteritis, age (less than 16 years old) and their hospitalization in Douala General Hospital paediatric infectious unit. The patients (boys and girls) were divided into three age groups: $0-5,6-10$ and $11-15$ years old.

\section{Samples}

Faecal specimen: liquid (diarrhoeic) or solid (non diarrhoeic) were obtained and refrigerated at $4{ }^{\circ} \mathrm{C}$ until they were analysed 2 to 24 hours after collection. When it was expected that the examination would be delayed for more than 24 hours after collection, the specimens were stored at -20 ${ }^{\circ} \mathrm{C}$ until examined.

\section{ELISA screening}

Supernatants of stools specimens were used for the screening of adenovirus by enzyme-linked immunosorbent assay (ELISA) with polyclonal test. The polyclonal antibodies could detect all adenoviruses regardless of serotype. ELISA screening test was done as described by Nishio et al., (1990). When the OD (optical density) value was 2 fold greater than the negative control, the sample was considered positive.

\section{Ethical considerations}

All work was performed according to the guidelines for human experimentation in clinical research stated by the ministry of public Health of Cameroon. The aim of the study was explained to each parent and those who signed informed consent were enrolled.

\section{RESULTS \\ Age distribution of patients}

A total of 65 faecal specimens were collected from infant and children hospitalized with acute gastroenteritis in the period October to December 2005 in the Douala General hospital. The age distribution of faecal specimens was: $58.5 \%$ (38/65 cases) for children of one month to 5 years, $20 \%(13 / 65$ cases) in the 6-10 year age and $21.5 \%$ (14/65 cases) in the 11-15 year age group (Table 1).

\section{Age distribution related to nature of faecal specimen}

Out of the 65 specimens, 25 cases $(38.5 \%)$ were diarrhoeic and 40 cases $(61.5 \%)$ none diarrhoeic. The age distribution according to the nature of faecal specimen was $47.4 \%$ and $52.6 \%$ respectively for diarrhoeic and none diarrhoeic faeces for children of one month to 5 years, $15.4 \%$ and $84.6 \%$ respectively for diarrhoeic and none diarrhoeic in the 6-10 year age group and $35.5 \%, 64.3 \%$ respectively for diarrhoeic and none diarrhoeic in the 11-15 year age group (Table 1).

Table 1: Characteristic of specimen according to age group

\begin{tabular}{|c|c|c|c|c|c|c|}
\hline \multirow{3}{*}{$\begin{array}{c}\text { Age group } \\
\text { (years) }\end{array}$} & \multicolumn{6}{|c|}{ Fecal specimen } \\
\hline & \multicolumn{2}{|c|}{ Fecal distribution } & \multicolumn{2}{|c|}{ Diarrhoeic feces } & \multicolumn{2}{|c|}{$\begin{array}{c}\text { Non } \\
\text { Diarrhoeic feces }\end{array}$} \\
\hline & $\mathbf{n}$ & $\%$ & $\mathbf{n}$ & $\%$ & $\mathbf{n}$ & $\%$ \\
\hline $0-5$ & 38 & 58.5 & 18 & 47.4 & 20 & 52.6 \\
\hline $6-10$ & 13 & 20.0 & 2 & 15.4 & 11 & 84.6 \\
\hline $11-15$ & 14 & 21.5 & 5 & 35.7 & 9 & 64.3 \\
\hline Total & 65 & 100.0 & 25 & 38.5 & 40 & 61.5 \\
\hline
\end{tabular}


Table 2: Incidence of adenovirus infection according to age group

\begin{tabular}{cccccc}
\hline \multirow{2}{*}{$\begin{array}{c}\text { Age group } \\
\text { (years) }\end{array}$} & \multicolumn{4}{c}{ Fecal specimen } \\
\cline { 2 - 3 } & \multicolumn{2}{c}{ Fecal distribution } & & Adenovirus Infection \\
\cline { 2 - 3 } \cline { 5 - 6 } & $\mathbf{n}$ & $\%$ & & $\mathbf{n}$ & $\%$ \\
$0-5$ & 38 & 58.5 & & 17 & 44.7 \\
$6-10$ & 13 & 20.0 & & 4 & 30.8 \\
$11-15$ & 14 & 21.5 & & 7 & 50.0 \\
Total & 65 & 100.0 & & 28 & 43.1 \\
\hline
\end{tabular}

\section{Detection of enteric adenovirus}

All faecal specimens were tested for the presence of adenovirus by ELISA test. The results shown in Table 2 revealed that enteric adenovirus was detected in 28/65 cases tested $(43.1 \%)$. Out of the 28 cases, the prevalence rate of enteric adenovirus was $44.7 \%, 30.8 \%$ and $50.0 \%$ for infant not more than 5 year old, 6-10 year age group and 11-15 year age group, respectively (Table 2 ).

\section{DISCUSSION}

Adenovirus is one of the enteropathogen responsible for viral gastroenteritis among infant and children in developed and developing countries. Even though numerous reports of enteric adenovirus infection in many countries have been published, there is no specific epidemiological data for illness caused by this virus in Cameroon. In this study, $43.1 \%$ of acute gastroenteritis was tested positive to enteric adenovirus but it does not determine this virus to be the sole causative agent of acute gastroenteritis, perhaps a larger proportion will be tested positive to rotavirus. In any case, there are possibilities of co-infections not just with viruses but also bacteria (Campylobacter, E.coli, and Shigella). This finding may suggests that about $43.1 \%$ of acute gastroenteritis in infant and children was due to adenovirus even other possible etiologic agents were not tested and that all diarrhoea does not have infectious origin. These data, according to the worldwide prevalence, confirm the importance of adenovirus as viral pathogen of enteric disease in paediatric patients (Waters et al., 2000; Parashar et al., 2003; Fodha et al., 2006; Reither et al., 2007). This tendency was clearly observed in this study, since the highest incidence of enteric adenovirus gastroenteritis (17/28 cases) was found in the
0-5 year old group which represented 58.5\% of the study patients with acute gastroenteritis. Our observation of high rate of incidence of enteric adenovirus infection in this group have been related to limited breastfeeding, low income, and socio-economic change, hygiene, dirty water and by other factors like early savage, malnutrition, co-infection with bacteria in others studies (Mulholland, 2004; Thapar and Sanderson, 2004). In this case, infants might probably not have enough maternally acquired passive antibodies against viral enteropathogens (Maria et al., 2004). $50.0 \%$ (data not shown) of infected stools were non diarrhoeic faeces. This result is probably due to the frequency of shedding of adenovirus in asymptomatic children that can be determined by ELISA or by existence of 52 adenovirus serotype. All serotypes of adenovirus do not determine diarrhoea but have hexon antigen. Rotaviruses and enteric adenovirus have been proven to be important causes of gastroenteritis in young children under the age of 5 years throughout the world. In Africa, rotavirus and enteric adenovirus are the commonest cause of severe diarrhoea and a leading cause of mortality in children and infant as shown in others studies (Audu et al.,2002; Fodha et al., 2006; Reither et al., 2007),. Our data show that enteric adenovirus is common virus related with gastroenteritis. Our epidemiological data will contribute to assess the magnitude of the problem of enteric adenovirus and rotavirus infection in different settings in Cameroon. A long period and seasonal study will certainly be useful to set priorities for intervention such as prevention strategies.

\section{REFERENCES}

Audu R, Omilabu AS, Peenze I, Steele DA. 2002. Isolation and identification of adenovirus recovered from the stool of 
children with diarrhoea in Lagos, Nigeria. Afr. J. Health Sci., 9(1-2): 105-111.

Cruz JR., Ca'ceres P, Cano F, Flores J, Bartlett A, and Toru'n B. 1990.Adenovirus types 40 and 41 and rotaviruses associated with diarrhea in children from Guatemala. J. Clin. Microbiol., 28: 1780-1784.

De Jong JC, Bijlsma K, Wermenbol AG, Verweij-Uijterwaal MW, Vander Avoort HG, Wood DJ, Bailey AS, Osterhaus AD.1993. Detection, typing and subtyping of enteric adenoviruses 40 and 4 from fecal samples and observation of changing incidences of infections with these types and subtypes. J. Clin. Microbiol., 31: 1562-1569.

De Jong JC, Wermenbol AG, VerweijUijterwaal MW, Stalateus KW, WertheinVan DP, Van-Doornum GJ, Khoo SH, Hierholzer JC.1999. Adenoviruses from human immunodeficiency virus-infected individuals, including two strains that represent new candidate serotypes Ad50 and Ad51 of species B1 and D, respectively. J. clin. Microbiol., 37: 39403945.

Fodha I, Chouikha A, Peenze I, De Beer M, Dewar J, Geyer A, Messaadi F, Trabelsi A, Boujaafar N, Taylor MB, Steele D.2006. Identification of viral agents causing diarrhea among children in the Eastern Center of Tunisia. J. Med. Virol., 78(9): 1198-1203.

Jarecki-Khan K, Tzipori SR, and Unicomb LE. 1993. Enteric adenovirus infection among infants with diarrhea in rural Bangladesh. J. Clin. Microbiol., 31: 484489.

Kapikian AZ, Hoshino Y, Chanock RM. 2001. Rotaviruses. In Field's Virology (4th edn). Knipe DM, Howley PM, Griffin DE (eds). Lippincott, Williams and Wilkins: Philadelphia; 1787-1833.

Maria CM, Monica M, Maria CA, Federica P, Flora De C, Icilio D, Raffaele V, Laura AA, Annalisa A, Laura Z, Pierpaolo V, Adriana C, Sergio B, Gian Carlo I, Giuseppe D, Carlo C. 2004. Epidemiological aspects of human rotavirus infection in children hospitalized with acute gastroenteritis in an area of northern Italy. Acta Bio Medica Ateneo Parmense, 75: 100-106.

Moore P, Steele AD, Lecatsas G, Alexander JJ. 1998. Characterization of gastroenteritis-associated adenoviruses in South Africa. S. Afr. Med. J., 88: 1587-1592.

Mulholland E. 2004. Global control of rotavirus disease. Exp. Med. Biol., 49: 161-168.

Nguendo YHB. 2007. Les maladies diarrhéiques: de l'épidémicité à l'endémicité. Médecine d'Afrique Noire, 54(8-9): 439-445.

Nishio O, Ooseto M, Takagi K, Yamasita Y, Ishihara y, Isomura S. 1990. Enzymelinked immunosorbent assay employing monoclonal antibodies for direct identification of enteric adenovirus (Ad40, 41) in feces. Microbiol. Immunol., 34: 871-877.

Parashar U, Bresee J, Glass R. 2003. The global burden of diarrhoeal disease in children. Bull. World Health Org., 81: 236-240.

Reither K, Ignatius R, Weitzel T, SeiduKorkor A, Anyidoho L, Saad E, DjieMaletz A, Ziniel P, Amoo-Sakyi F, Danikuu F, Danour S, Otchwemah RN, Schreier E, Bienzle U, Stark K, Mockenhaupt FP. 2007. Acute childhood diarrhoea in northern Ghana: epidemiological, clinical and microbiological characteristics. $B M C$ Infect. Dis., 6(7): 104.

Schnurr D, Dondero ME. 1993. Two new candidate adenovirus serotypes. Intervirology., 36: 2113-2116.

Thapar N, Sanderson I. 2004. Diarrhoea in Children: an interface between developing and developed countries. Lancet, 363: 641-653.

Waters V, Ford-Jones EL, Petric M, Fearon M, Corey P, Moineddein R. 2000. Etiology of community-acquired pediatric viral diarrhea: a prospective longitudinal study in hospitals, emergency departments, pediatric pratices and child care centers during the winter rotavirus outbreak, 1997 to 1998. Pediatr. Infect. Dis. J., 19: 843-848. 